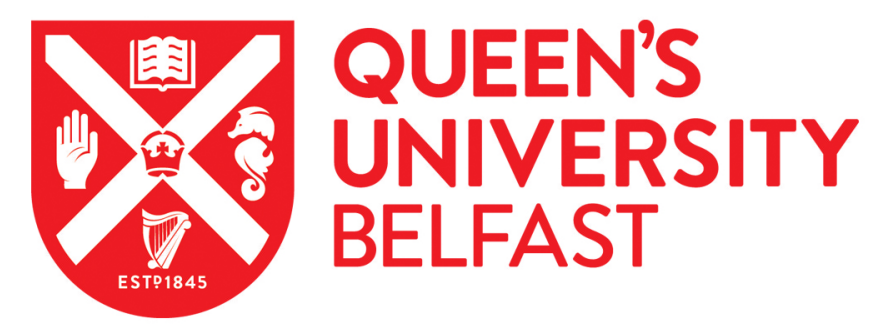

\title{
Comparison of power system stabilizer design based on local and global model
}

Lv, C., Du, W., \& Littler, T. (2016). Comparison of power system stabilizer design based on local and global model. In Proceedings of the IET International Conference on Renewable Power Generation (RPG2015) IET. https://doi.org/10.1049/cp.2015.0368

Published in:

Proceedings of the IET International Conference on Renewable Power Generation (RPG2015)

Document Version:

Peer reviewed version

Queen's University Belfast - Research Portal:

Link to publication record in Queen's University Belfast Research Portal

Publisher rights

@ 2015 IET/IEEE, and This work is made available online in accordance with the publisher's policies. Please refer to any applicable terms of use of the publisher.

\section{General rights}

Copyright for the publications made accessible via the Queen's University Belfast Research Portal is retained by the author(s) and / or other copyright owners and it is a condition of accessing these publications that users recognise and abide by the legal requirements associated with these rights.

Take down policy

The Research Portal is Queen's institutional repository that provides access to Queen's research output. Every effort has been made to ensure that content in the Research Portal does not infringe any person's rights, or applicable UK laws. If you discover content in the Research Portal that you believe breaches copyright or violates any law, please contact openaccess@qub.ac.uk. 


\title{
COMPARISON OF POWER SYSTEM STABILIZER DESIGN BASED ON LOCAL AND GLOBAL MODEL
}

\author{
C. $L v^{*}$, W. Du $u^{\dagger}$, T. Littler* \\ ${ }^{\star}$ Queen's University Blefast, $U K$ \\ clv01@qub.ac.uk;t.littler@ee.qub.ac.uk \\ $\dagger$ North China Electric Power University, Beijing, China
}

Keywords: Small-signal stability, power system stabilizer, low-frequency oscillations, global model, localized phase compensation method.

\begin{abstract}
This paper introduces a localized phase compensation method for the design of power system stabilizers (PSSs) to suppress the oscillation occurred in a single-machine infinite-bus (SMIB) power system. The proposed method is used to design stabilizers to suppress power system oscillations and only requires the available generator and transformer parameters thus eliminating the need to receive and verify entire power system parameters. This paper establishes the extended linear Phillips-Heffron model for a SMIB system with a PSS installed in the generator and demonstrates application of the model to determine damping and thus preserve power system oscillation stability. The paper also presents several examples where the proposed method has been used with two models to design PSSs with comparative results presented in a case study.
\end{abstract}

\section{Introduction}

Power system low-frequency oscillations threaten the security of power system operation as in some cases they may interrupt stable operation of systems. One effective way of suppressing the oscillations is that the auxiliary controllers which formed power system stabilizers (PSSs) are installed in the excitation power system of generators, to provide additional damping to the low-frequency power oscillations [1-2]. Since 1970s a variety of design procedures and algorithms have been proposed for the design of power system stabilizers using either linear or nonlinear models of power system.

On the basis of the damping torque principle, Gibbard [3-5] and Wang [6-7] have investigated the stabilizer design based on global model of power system. For a long time period, damping torque principle has been considered as an engineering heuristics [8]. However, it needs the parameters of the whole network and the generators to apply the method of modal analysis. Thus the extension of the phase compensation method becomes very complicated and the simplicity of the global model is lost. That is the reason why that the modal analysis has been more often used for the design of stabilizers to suppress the inter-area power oscillation in systems.
Recently Gurrala and Sen suggested one approach which employs the secondary bus voltage of generator's step-up transformer to establish a Phillips-Heffron model and applying the phase compensation method to design [9]. The application not only keeps the advantage of simplicity of the global phase compensation method, but also does not require the information of complete power system, which in practice may not always be readily available and is difficult to be validated when the system scale is large and complex [10-11].

This paper introduces a localized phase compensation method for the design of power system stabilizers (PSSs) to suppress the oscillation occurred in a single-machine infinite-bus (SMIB) power system. The proposed method is used to design stabilizers to suppress power system oscillations and only requires the available generator and transformer parameters thus eliminating the need to receive and verify entire power system parameters. This paper establishes the extended linear Phillips-Heffron model for a SMIB power system with a PSS installed in the generator and demonstrates applications of the model on aspects of damping determination and thus power system oscillation stability preservation. This paper also presents several examples where the proposed method has been used with two models to design PSSs with comparative results presented in a case study.

\section{Local and global model of power system}

\subsection{Local model}

Fig.1 shows a single-machine infinite-bus power system with one transformer.

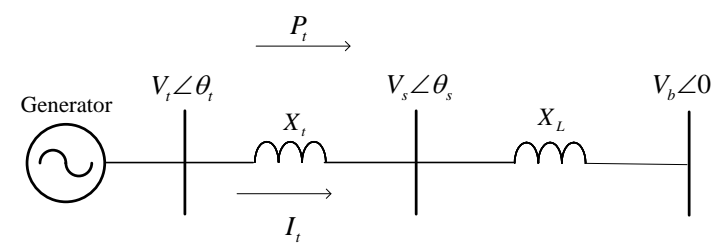

Figure 1: Single-machine infinite-bus power system

The system shown in figure 1 is used to obtain the linearized dynamic model (extended Phillip-Heffron model). The dynamic equations of the power system are as follows: 


$$
\begin{aligned}
& \dot{\delta}=\omega_{0}(\omega-1) \\
& \dot{\omega}=\frac{1}{M}\left[P_{M}-P_{t}-D(\omega-1)\right] \\
& \dot{E}_{q}^{\prime}=\frac{1}{T_{d 0}^{\prime}}\left(-E_{q}+E_{f d}\right) \\
& \dot{E}_{f d}^{\prime}=-\frac{1}{T_{A}} E_{f d}^{\prime}+\frac{K_{A}}{T_{A}}\left(V_{r e f}-V_{t}+u_{p s s}\right)
\end{aligned}
$$

Where

$$
\begin{aligned}
& P_{t}=E_{q}^{\prime} i_{q}+\left(X_{q}-X_{d}^{\prime}\right) i_{d} i_{q} \\
& E_{q}=E_{q}^{\prime}+\left(X_{d}-X_{d}^{\prime}\right) i_{d} \\
& E_{f d}=E_{f d 0}+E_{f d}^{\prime} \\
& V_{t d}=X_{q} i_{q} \\
& V_{t q}=E_{q}^{\prime}-X_{d}^{\prime} i_{d}
\end{aligned}
$$

Fig.2 shows the local Phillips-Heffron model of singlemachine infinite-bus power system.

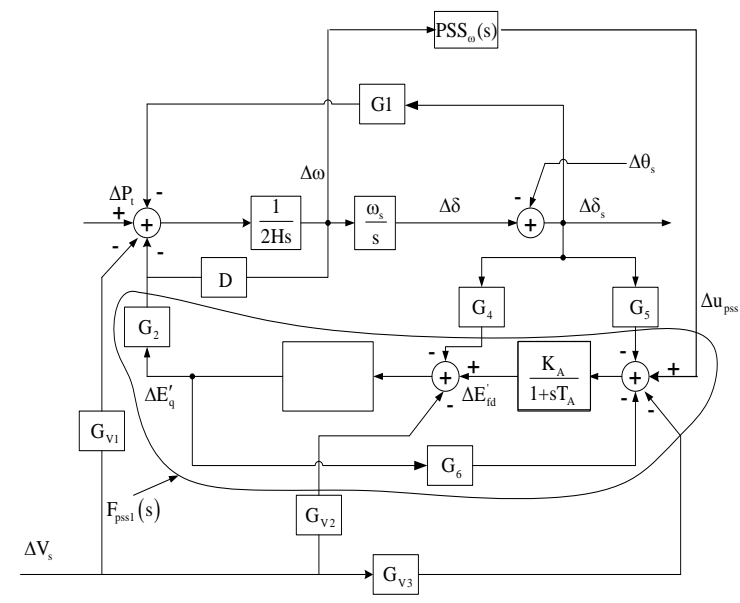

Figure 2: Local Phillips-Heffron model of SMIB power system

The reference axis of local model is $V_{s}$ in power system, with the reactance of transmission line $X_{L}$ ignored.

Linearization of Eq.(1), it can be obtained that:

$$
\begin{aligned}
& \Delta \dot{\delta}=\omega_{0} \Delta \omega \\
& \Delta \dot{\omega}=\frac{1}{M}\left(-G_{1} \Delta \delta_{s}-G_{2} \Delta E_{q}^{\prime}-G_{V 1} \Delta V_{s}-D \Delta \omega\right) \\
& \Delta \dot{E}_{q}^{\prime}=\frac{1}{T_{d 0}^{\prime}}\left(-G_{3} \Delta E_{q}^{\prime}-G_{4} \Delta \delta_{s}-G_{V 2} \Delta V_{s}+\Delta E_{f d}\right) \\
& \Delta \dot{E}_{f d}^{\prime}=-\frac{1}{T_{A}} \Delta E_{f d}+\frac{K_{A}}{T_{A}}\left(-G_{5} \Delta \delta_{s}-G_{6} \Delta E_{q}^{\prime}-G_{V 3} \Delta V_{s}+\Delta u_{p s s}\right)
\end{aligned}
$$

The parameters of PSS can be set to satisfy with phase compensation method for the PSS to provide a pure positive damping torque. The forward path of the output signal of PSS is given as follow:

$$
F_{p s s 1}(s)=\frac{G_{2} K_{A}}{\left(G_{3}+j \omega_{s} T_{d 0}^{\prime}\right)\left(1+j \omega_{s} T_{A}\right)+G_{6} K_{A}} .
$$

$$
\begin{gathered}
G_{2}=i_{q 0}\left(1-\frac{X_{d}^{\prime}-X_{q}}{X_{d}^{\prime}+X_{t}}\right)=\frac{X_{q}+X_{t}}{X_{d}^{\prime}+X_{t}} i_{q 0} \\
G_{3}=\frac{X_{d}+X_{t}}{X_{d}^{\prime}+X_{t}} \\
G_{6}=\frac{V_{t q 0} X_{t}}{V_{t 0}\left(X_{d}^{\prime}+X_{t}\right)}
\end{gathered}
$$

The damping torque contributed by PSS to the electromechanical oscillation loop is $D_{p s s 1}$. Then the parameters of PSS are set by phase compensation method:

$$
\begin{aligned}
& K_{p s s 1} \frac{\left(1+j \omega_{s} T_{2}\right)}{\left(1+j \omega_{s} T_{1}\right)}=\frac{D_{p s s 1}}{F_{p s s}} \angle-\frac{\phi}{2} \\
& K_{p s s 2} \frac{\left(1+j \omega_{s} T_{4}\right)}{\left(1+j \omega_{s} T_{3}\right)}=1.0 \angle-\frac{\phi}{2}
\end{aligned} .
$$

And the dynamic equations are shown below:

$$
\begin{aligned}
& \Delta y=K_{p s s 2} \frac{1+s T_{4}}{1+s T_{3}} \Delta \omega \\
& \Delta u_{p s s}=K_{p s s 1} \frac{1+s T_{2}}{1+s T_{1}} \Delta y
\end{aligned}
$$

From computational results above, the state equation of the power system with full mathematical model of the generator applied can be established as follow:

$$
\dot{\mathbf{X}}=\mathbf{A}_{g} \mathbf{X} \text {. }
$$

$\mathbf{A}_{g}$ is the closed-loop matrix of power system installed with PSS.

Thus, the local oscillation mode is moved to $\lambda_{g}=\xi_{g}+j \omega_{g}$ based on the local model of power system installed with a PSS.

\subsection{Global model}

The reference axis of global model is $V_{b}$, and the reactance of transformer and transmission line is $X_{L}+X_{t}$. Hence the linearization of simplified global model in power system is:

$$
\begin{aligned}
& \Delta \dot{\delta}=\omega_{o} \Delta \omega \\
& \Delta \dot{\omega}=\frac{1}{M}\left(-K_{1} \Delta \delta-K_{2} \Delta E_{q}{ }^{\prime}-D \Delta \omega\right) \\
& \Delta \dot{E}_{q}{ }^{\prime}=\frac{1}{T_{d o}{ }^{\prime}}\left(-K_{3} \Delta E_{q}{ }^{\prime}-K_{4} \Delta \delta+\Delta E_{f d}{ }^{\prime}\right) \\
& \Delta \dot{E}_{f d}{ }^{\prime}=-\frac{1}{T_{A}} \Delta E_{f d}{ }^{\prime}-\frac{K_{A}}{T_{A}}\left(K_{5} \Delta \delta+K_{6} \Delta E_{q}{ }^{\prime}-\Delta u_{p s s}\right)
\end{aligned}
$$

Fig. 3 shows the global Phillips-Heffron model of singlemachine infinite-bus power system.

Where 


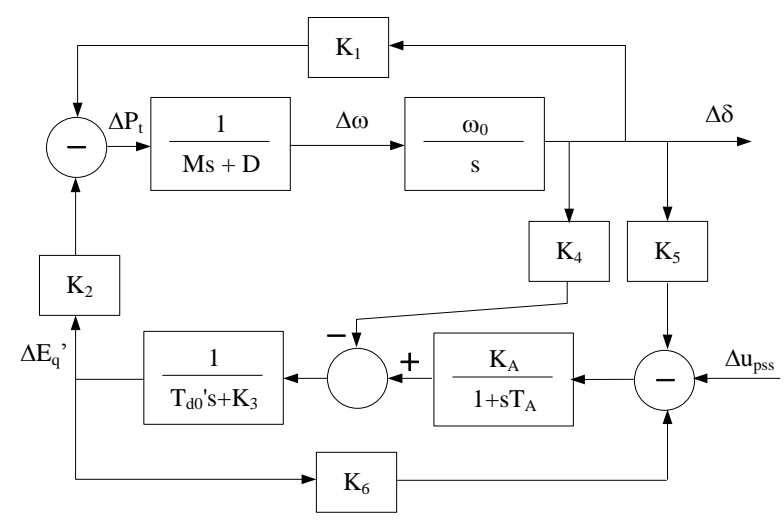

Figure 3: Global Phillips-Heffron model of SMIB power system

The power system stabilizer (PSS) can be designed by using the method of phase compensation and installed to provide a pure damping torque $D_{p s s 2}$. The expression for the forward path is given by:

$$
F_{p s s 2}(s)=\frac{K_{2} K_{A}}{\left(K_{3}+j \omega_{s} T_{d 0}^{\prime}\right)\left(1+j \omega_{s} T_{A}\right)+K_{6} K_{A}} .
$$

Where

$$
\begin{gathered}
K_{2}=\frac{V_{b}}{X_{d}^{\prime}+X_{t}+X_{L}} \sin \delta_{0} \\
K_{3}=\frac{X_{d}+X_{t}+X_{L}}{X_{d}^{\prime}+X_{t}+X_{L}} \\
K_{6}=\frac{V_{t q 0}}{V_{t 0}} \frac{X_{t}+X_{L}}{X_{d}^{\prime}+X_{t}+X_{L}}
\end{gathered}
$$

The PSS design based on global model is the same as it is in Eq.(5). From computational results above, the state equation of the power system with full mathematical model of the generator applied can be established as follow:

$$
\dot{\mathbf{X}}=\mathbf{A}_{k} \mathbf{X} \text {. }
$$

$\mathbf{A}_{k}$ is the closed-loop matrix of power system installed with a PSS.

Thus, the global oscillation mode is moved to $\lambda_{k}=\xi_{k}+j \omega_{k}$ based on the global model of power system installed with a PSS.

\section{Case Study}

\subsection{The comparison between local and global model with different load conditions}

From Eq.(4) and Eq.(9), the transfer function of the forward path of the stabilizer at the oscillation frequency is calculated as follows:

$$
\begin{gathered}
F_{p s s 1}=0.1995-j 0.5166=0.5524 \angle-69.2744^{\circ} \\
G_{2}=0.8094 G_{3}=2.5000 G_{6}=0.4673 \\
F_{p s s 2}=0.1781-j 0.3998=0.4376 \angle-65.9867^{\circ} \\
K_{2}=0.6871 K_{3}=2.0000 \quad K_{6}=0.6199
\end{gathered}
$$

And from Eq.(7) and Eq.(10), the oscillation modes of singlemachine infinite-bus power system are shown in tables below:

\begin{tabular}{|c|c|}
\hline & Oscillation mode \\
\hline Without the stabilizer & $-0.0821 \pm j 5.4072$ \\
\hline With the stabilizer & $-0.6911 \pm j 5.2783$ \\
\hline
\end{tabular}

Table 1: Local Oscillation mode of power system

\begin{tabular}{|c|c|}
\hline & Oscillation mode \\
\hline Without the stabilizer & $-0.0896 \pm j 5.6643$ \\
\hline With the stabilizer & $-0.7478 \pm j 5.5886$ \\
\hline
\end{tabular}

Table 2: Global Oscillation mode of power system

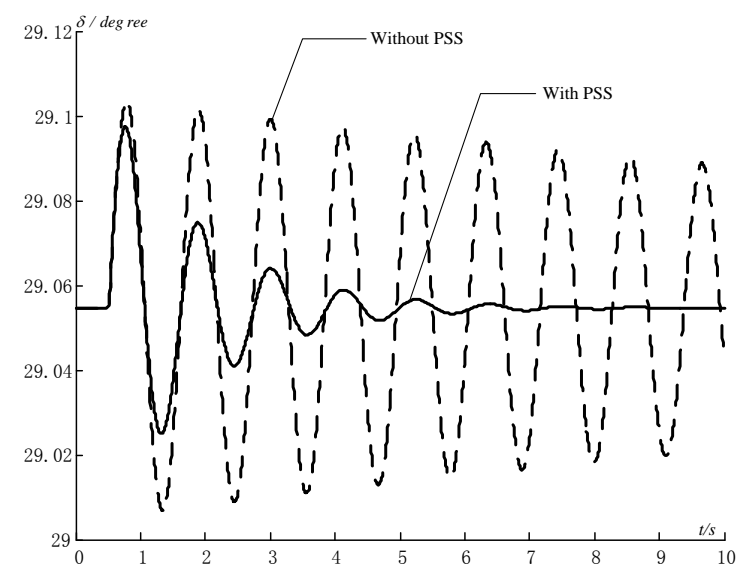

Figure 4: Simulation results of oscillation modes based on local model with or without a PSS installed

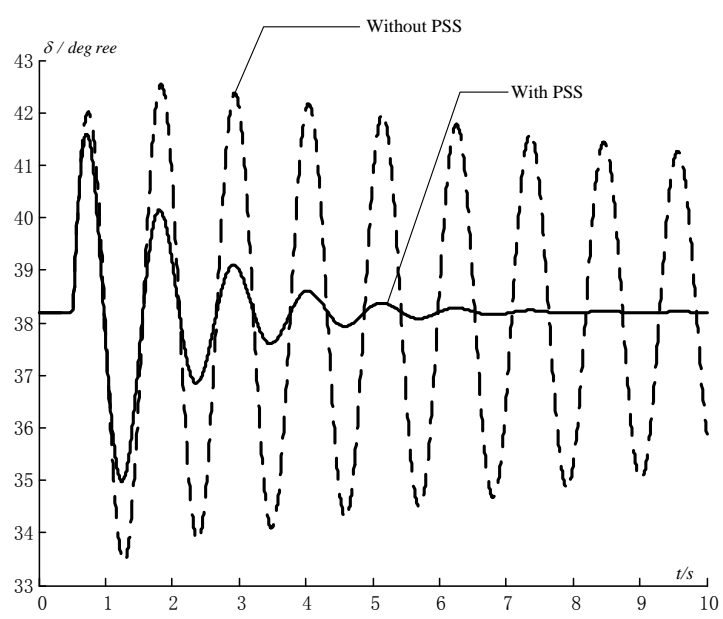

Figure 5: Simulation results of oscillation modes based on global model with or without a PSS installed

To validate the effectiveness of the stabilizer, table 1 gives the computational results of the local oscillation mode of the power system and table 2 gives the computational results of the global oscillation mode of the power system. Figure 4 and figure 5 show the non-linear simulation results of local and global of the power system respectively. 
Then the load condition is changed from 0.2 to 0.8 per unit in power system. Table 3 and table 4 give the local oscillation modes and global oscillation modes in power system under different load conditions.

\begin{tabular}{|c|c|}
\hline $\begin{array}{c}\text { Load condition (per unit) } \\
P_{t 0}\end{array}$ & Oscillation mode $\bar{\lambda}_{g}$ \\
\hline 0.2 & $-0.3280 \pm j 5.2983$ \\
\hline 0.5 & $-0.6911 \pm j 5.2783$ \\
\hline 0.8 & $-0.8657 \pm j 5.2467$ \\
\hline
\end{tabular}

Table 3: Local oscillation mode with different load condition

\begin{tabular}{|c|c|}
\hline $\begin{array}{c}\text { Load condition (per unit) } \\
P_{t 0}\end{array}$ & Oscillation mode $\bar{\lambda}_{k}$ \\
\hline 0.2 & $-0.3535 \pm j 5.3314$ \\
\hline 0.5 & $-0.7476 \pm j 5.5888$ \\
\hline 0.8 & $-0.9161 \pm j 5.7171$ \\
\hline
\end{tabular}

Table 4: Global oscillation mode with different load condition

Above of all, it can be seen that two stabilizers are designed successfully by using the phase compensation method. The power oscillation is effectively suppressed by the stabilizer installed in the generator. The stabilizer designed based on local model of power system retain the robustness of the one designed based on global model in terms of damping oscillations.

\subsection{Influence of transmission line with local and global model}

The reactance of transmission line is changed from 0.3 to 0.6 per unit and the other parameters of power system remain unchanged. From Eq.(4) and Eq.(9), the transfer functions of the forward path of the stabilizers at the oscillation frequency are calculated to be:

$$
\begin{gathered}
F_{p s s 1}=0.2672-j 0.5740=0.6331 \angle-65.0376^{\circ} \\
G_{2}=0.8094 G_{3}=2.5000 \quad G_{6}=0.4673 \\
F_{p s s 2}=0.2074-j 0.3624=0.4176 \angle-60.2158^{\circ} \\
K_{2}=0.6076 K_{3}=1.7500 \quad K_{6}=0.6981
\end{gathered}
$$

Fig.6 and fig. 7 show the simulation results of local model and global model respectively. Compared with the previous power system $\left(X_{L}=0.3\right.$ ), the values of parameters in global model ( $\left.K_{2}, K_{3}, K_{6}\right)$ are changed, and the values of parameters in local model $\left(G_{2}, G_{3}, G_{6}\right)$ are invariable. It is found that the global model is influenced by transmission line reactance so that the design of PSS is inaccurate. Thus, the local oscillation mode is $\lambda_{g}=-0.5750 \pm j 4.4237$ and the global oscillation mode is $\lambda_{k}=-0.5677 \pm j 4.8813$.

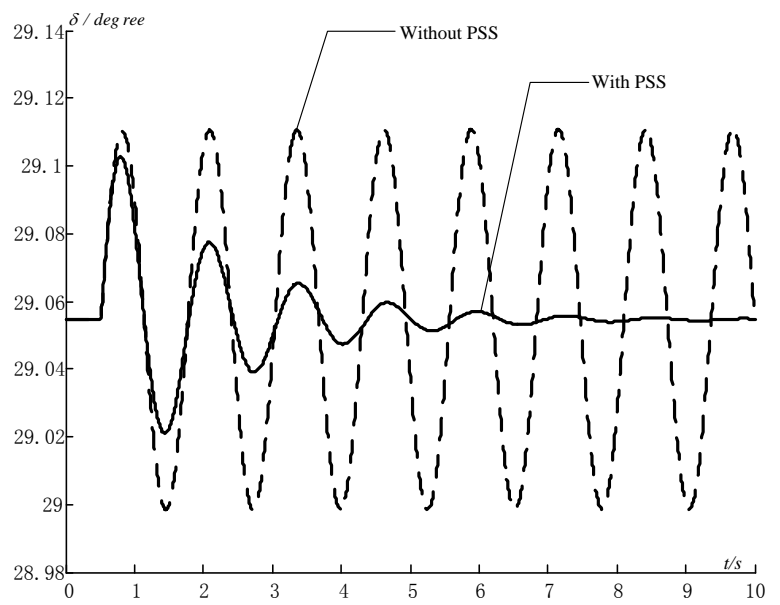

Figure 6: Simulation results without/with PSS in local model when $X_{L}=0.6$

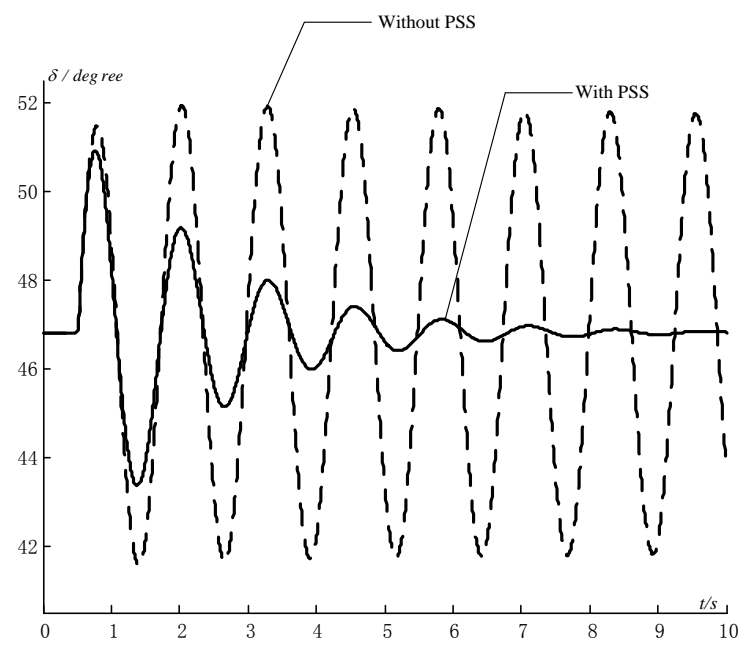

Figure 7: Simulation results without/with PSS in global model when $X_{L}=0.6$

From fig. 6 and fig.7, it can be obtained that: the local model can ignore the influence of transmission line reactance on power system, which is the advantage of local model for design power system stabilizer by using localized compensation method in SMIB power system to damp oscillations. Actually, it is difficult to measure the reactance of transmission line in the practical engineering so that the designing of PSS based on local model is better than the global model in power system.

\section{Conclusion}

Power system stabilizer is always a local power device, and most of design methods must rely on a mathematical model of 
the whole power system which is known as global model. This paper proposes a localized phase compensation method, which only requires the locally available information of the generator and the transformer. Thus it avoids the difficulty to obtain and validate the complete power system information for design of the stabilizers. The simulation result of designing a stabilizer attached on the generator in a single machine infinite-bus power system by using the proposed method is given in the case study. Comparison between the results obtained by local and global model validates the success of localized phase compensation method to design the stabilizers and can be used to effectively suppress power oscillations. The robustness of localized phase compensation method based on the local model is the same as conventional phase compensation method based on the global model in terms of design of power system stabilizer in power system. It is found that the local model can ignore the influence of transmission line reactance in power system, which is the advantage of local model for design power system stabilizer by localized compensation method in SMIB power system. As it is difficult to measure the reactance of transmission line in the practical engineering, the PSS design based on local model is better than the global model in power system.

\section{Acknowledgements}

The author would like to acknowledge the financial support of the Science Bridge Project funded by the UKRC and the Queen's University of Belfast, UK, and the National Basic Research Program of China (973Program)(2012CB215204).

\section{References}

[1] F. P. Dmello, C. Concordia. "Concept of synchronous machine stability as affected by excitation control", The Journal, IEEE Trans. Power App. Syst., 88, 4. 316-329,

[2] E. V. Larsen, D. A. Swann. "Applying power system stabilizers Part I, II and III", The Journal, IEEE Trans. Power App. Syst., 100, 6. 3017-3046, (1981).

[3] M. J. Gibbard. "Coordinated design of multi-machine power system stabilizers based on damping torque concepts", The Journal, IEE Pro. Part C, 135, 4. 276284, (1988).

[4] M. J. Gibbard, D. J. Vowles. "Reconciliation of methods of compensation for PSSs in multi-machine systems", The Journal, IEE Trans. Power Syst., 19, 1. 463-472, (2004).

[5] M. J. Gibbard, D. J. Vowles and P. Pourbeik. "Interactions between and effectiveness of power system stabilizers and FACTS device stabilizers in multimachine systems", The Journal, IEE Trans. Power Syst., 15. 748-755, (2000).

[6] H. F. Wang, F. J. Swift and M. Li. "A unified model for the analysis of FACTS devices in damping power system oscillations part II: multi-machine power systems", The Journal, IEE Trans. Power Delivery, 13, 1. 1355-1362, (1988).

[7] W. J. Du, H. F. Wang. "Application of the phase compensation method for the design of a DC/AC converter based stabilizer to damp power system interarea oscillations", The Journal, IEE Trans. Power Syst., 27, 3. 1302-1310, (2012).

[8] H. F. Wang, F. J. Swift. "Multiple stabilizer setting in multi-machine power systems by the phase compensation method", The Journal, Electrical Power and Energy Systems, 20, 4. 241-246, (1998).

[9] G. Gurrala, I. Sen. "Power system stabilizers design for interconnected power systems", The Journal, IEEE Trans. Power Syst., 25, 2. pp, (2010).

[10] W. G. Heffron, R. A. Phillips. "Effect of modern amplidyne voltage regulators on under excited operation of large turbine generators", The Journal, AIEE Trans. Power App Syst., 71. 692-697, (1952).

[11] K. R. Padiyar. "Power system dynamics stability and control", The Monograph, New York, Wiley, (1996).

\section{Appendix}

Parameters of example single-machine infinite-bus power system (in per unit except indicated):

\section{Generator}

$X_{d}=1.18, X_{q}=1.0, X_{a d}=1.0, X_{f}=1.13, X_{d}{ }^{\prime}=X_{d}-\frac{X_{a d}{ }^{2}}{X_{f}}=0.2951$,

$\mathrm{M}=7, D=0, T_{d 0}^{\prime}=5.044 \mathrm{~s}$

Transmission line

$X_{L}=0.3, X_{t}=0.3$

AVR

$T_{A}=0.01, K_{A}=20.0$ 